\title{
EVALUATION OF PATIENTS PRESENTING TO THE OPHTHALMOLOGY DEPARTMENT OF A TERTIARY HOSPITAL FOR NONEMERGENCY REASONS DURING THE COVID-19 PANDEMIC
}

\author{
Aslan F., Öktem C. \\ Alaaddin Keykubat University Alanya Education and Research \\ Hospital, Department of Ophthalmology Antalya, TURKEY \\ Funding: This study had no funding. \\ Ethical approval: The study procedures were carried out in accordance \\ with the Helsinki Declaration. The study protocol was approved by \\ the Alanya Alaaddin Keykubat University Clinical Research Ethics \\ Committee (No. 10354421 dated 2019/2). \\ Conflict of Interest: All authors declare no conflict of interest.
}

Do redakce doručeno dne: 10. 8. 2020

Prijiato k publikaci dne: 27. 10. 2020

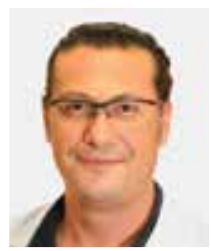

Aslan Fatih, MD Alaaddin Keykubat University Alanya Education and Research Hospital, Department of Ophthalmology, 07400 Antalya

\section{SUMMARY}

Objective: To evaluate changes in the demographic and diagnostic distribution of patients presenting to the ophthalmology department during the COVID-19 pandemic, compared to the pre-pandemic period.

Methods: The study included patients who made outpatient appointments in our ophthalmology department. The COVID-19 group (CovG) comprised patients who presented between April 15 and May 15, 2020, the 30-day period with the highest daily number of new cases in Turkey. The control group (CG) was obtained by randomization through a computer program from among 2245 patients who applied in the same period of the previous year. The patients' presenting complaint(s), diagnostic(s) and demographic information's were collected from a database, with all identifying information concealed. For patients who presented more than once, their initial complaint and diagnoses were analyzed.

Results: The study included a total of 400 patients: 200 in the CovG and 200 in the CG. Mean ages in the CovG and CG were $41.23 \pm 14.48$ and 48.20 \pm 17.49 years, respectively $(p<0.001)$. The female to male patient ratio was 0.53 in the CovG and 0.83 in the CG $(p=0.032)$. There were fewer university graduates compared to other education levels among the patients who presented during the pandemic $(p=0.013)$. During the COVID-19 pandemic, there was no increase in presentation frequency for any ocular disease compared to the previous year.

The only statistical decrease in patient application complaints was observed in reading difficultness ( $11 \%$ in CovG vs. $37 \%$ in CG; $p<0.001)$. Presentations due to dry eye (DE) and allergic conjunctivitis (AC) were similar to the same period of the year $(p=0.303$ and $p=0.550$, respectively). At least 1 chronic ocular disease was present in $25 \%$ of the CovG and $45.5 \%$ of the CG ( $p<0.001)$. A statistically significant decrease was observed in CovG for age-related macular degeneration and glaucoma in the diagnoses made at the end of the examination $(p=0.001$ and $p<0.001$, respectively).

Conclusion: During the first peak of the COVID-19 pandemic in Turkey, the most common outpatient presentations to the ophthalmology department were for the diagnoses of DE and AC. During peak pandemic period, elderly patients, women and academically trained patients significantly reduced their visits to the Eye Clinic. The reduction in presentation of patients with glaucoma and age-related macular degeneration may be due to the longterm treatment planning for these patients and the social isolation measures issued for the older population. These patients should be encouraged to use video consultation / telemedicine in eye patients at risk of vision loss.

Key words: COVID-19, pandemic, ophthalmological diseases, diagnosis distribution, epidemiology, risk perception

Čes. a slov. Oftal., 76, 2020, No. 6, p. 260-264

\section{INTRODUCTION}

The 2019 coronavirus disease (COVID-19) first emerged in Wuhan, China in December 2019 and within a short time, had affected the whole world. The virus was named "severe acute respiratory syndrome coronavirus 2" (SARSCoV-2) by the International Committee on Taxonomy of Viruses [1]. The first case in Turkey was reported on March 11,2020 , the same day that the World Health Organization (WHO) declared COVID-19 a global pandemic [2,3].
After the first case was confirmed in Turkey, the government implemented staged social isolation measures. Education was provided at home via distance learning, lockdowns were issued for individuals over 65 and below 20 years of age, and flexible working models were adopted in government institutions including hospitals, with the exception of critical units such as emergency services [4]. The main measure taken was the general lockdown during weekends except for health workers and providers of essential services. All citizens were advised to "stay 
home" through all media channels, while at the same time, physicians' working arrangements were altered, continuing with one-third of their previous caseload through the flexible working model [5]. The centralized hospital appointment system was open during the pandemic and patients could make outpatient clinic appointments.

During the pandemic, the American Academy of Ophthalmology recommended limiting outpatient services and developing mechanisms to prioritize elective procedures, until the outbreak becomes under control [6]. Similarly, the Turkish Ophthalmological Association published a guide for ophthalmologists in the field regarding measures to take in outpatient clinic practices and the management of urgent eye diseases, during the pandemic [7].

A series of studies have been conducted to isolate the virus from tear samples or ocular surface swabs and investigate ocular involvement [8-11].

The present study aimed to evaluate the changes in the frequency, profile and diagnostic spectrum of patients presenting to the ophthalmology department, which may be associated with COVID regulations, restrictions and individual variations in risk perception, among patients. In order to better understand our patients, we wanted to gain an insight into their motivation for seeking medical attention during such a risky period.

\section{METHOD}

In this single-center, cross-sectional, retrospective study, patient files were evaluated in accordance with the principles in the Declaration of Helsinki. Official approval for the study was obtained by the Turkish Ministry of Health's COVID-19 Scientific Research Evaluation Committee on June 17, 2020 (approval no: 2020-06-12T03_30_09). Ethical approval was granted by the ethics committee of the Alanya Alaaddin Keykubat University, Faculty of Medicine (No: 2020/20-13). As the study was retrospective, written consent could not be obtained from the patients, however all names and identifying information were concealed by the information technology team, and the ethics committee was duly informed of this fact.

The COVID-19 group (CovG) in this study included the records of 200 patients who made an appointment at the ophthalmology department of the Alanya Alaaddin Keykubat University Research and Training Hospital, between April 15 and May 15, 2020. A pre-COVID control group (CG) was created using the files of patients who made appointments at the same clinic a year before the pandemic, precisely between April 15 and May 15, 2019. In order to increase the effectiveness if the study, a randomized sample was selected among the patients with a 1/1 ratio from the sample group and from the control. Randomization was achieved by transferring 2245 patients who applied in the selected period to the SPSS program and determining the sample using the random selection method of the program.
The patients' age, sex, presenting complaint(s), presence of chronic ocular diseases, topical drug use were noted from the electronic database, as well as the ICD10 (International Classification of Diseases-10th Revision) codes. For patients who presented more than once within 10 days, only the first complaint and diagnosis were used in the analysis. Patients who received consultation over the phone, those who presented to the emergency department and those who presented for any reason to another department from which consultation by the ophthalmology outpatient clinic was requested, were excluded from the study.

Statistical analyses were performed using the SPSS Statistics version 17.0 software (SPSS Inc., Chicago, IL). Normal distribution of the variables was analyzed using histogram charts and the Kolmogorov-Smirnov test. Descriptive analyses were presented as mean, standard deviation, median and percentage values. Categorical variables were compared using Pearson's chi-square test, whereas the Mann-Whitney U test was used for comparisons of non-normally distributed (nonparametric) variables between the groups.

A p-value less than 0.05 was considered statistically significant. The power analysis was performed using G-power 3.0 and indicated that for a sample with unknown effect, a total sample size of 220 was sufficient for an alpha level of $5 \%$ and power of $95 \%$.

\section{RESULTS}

Appointments in the ophthalmology clinic accounted for $8.4 \%$ of all hospital appointments before the pandemic and $9.7 \%$ during the pandemic ( $p=0.277$ ). While there were 2245 patient applications before the pandemic, 200 patients were followed during the peak pandemic period. There was a $91 \%$ decrease in the frequency of referral to the Eye Clinic.

The study included a total of 400 patients: 200 in the CovG and 200 in the CG. The mean age of the patients was $48.20 \pm 17.49$ years in the CG and $41.23 \pm 14.58$ years in the $\operatorname{CovG}(p<0.001)$. The gender distribution changed significantly from $35 \%$ women and $65 \%$ men in the CG, to $45.5 \%$ women and $54.5 \%$ men in the CovG ( $p=0.032)$. Comparison of education levels between patients in the CovG and CG showed that the average education level was significantly higher among patients in the CG $(p=0.013)$. Table 1 . None of the patients had a history of COVID positivity.

The groups were compared in terms of reason for presenting: follow-up, burning/stinging, pain, redness, lid swelling, hyperopia, myopia, itching, crusting/discharge and diplopia. Significantly fewer patients in the CovG presented for routine follow-up ( $n=19,9.50 \%$ ) compared to the CG $(n=45,22.50 \%)(p<0.001)$. There were also fewer presentations resulting from farsightedness in the CovG $(n=22,11.00 \%)$ than in the CG $(n=74,37.00 \%)$ $(p<0.001)$. Table 2. 
Table 1. Comparison of demographic characteristics between ophthalmology outpatients before and during the COVID-19 pandemic

\begin{tabular}{|c|c|c|c|c|c|c|}
\hline & & \multicolumn{2}{|c|}{ CovG } & \multicolumn{2}{|c|}{ CG } & \multirow{2}{*}{$\mathbf{p}$} \\
\hline & & $\mathbf{n}$ & $\%$ & $\mathbf{n}$ & & \\
\hline \multicolumn{2}{|l|}{ Age, years } & $41.23 \pm 14.58$ & 41 & $48.20 \pm 17.49$ & 49.00 & $<0.001^{2}$ \\
\hline \multirow{2}{*}{ Sex } & Female & 91 & $(45.5)$ & 70 & (35) & \multirow{2}{*}{0.032} \\
\hline & Male & 109 & $(54.5)$ & 130 & (65) & \\
\hline \multirow{4}{*}{ Education level } & Illiterate & 9 & $(4.5)$ & 8 & (4) & \multirow{4}{*}{0.013} \\
\hline & Primary school & 57 & $(28.5)$ & 53 & (26) & \\
\hline & $\begin{array}{l}\text { Secondary } \\
\text { school }\end{array}$ & 125 & $(62.5)$ & 111 & (55.5) & \\
\hline & University & 9 & $(4.5)$ & 28 & (14) & \\
\hline
\end{tabular}

Chi-square test ${ }^{2}$ Mann-Whitney $U$ Test (mean \pm standard deviation is given instead of $n$, median is given instead \%);

Abbreviations: CovG: Group during COVID-19 pandemic, CG: Control group, pre-COVID-19

Table 2. Comparison of reasons for presenting among ophthalmology outpatients before and during the COVID-19 pandemic

\begin{tabular}{|c|c|c|c|c|c|}
\hline \multirow{2}{*}{ Reason for Presenting } & \multicolumn{2}{|c|}{ CovG } & \multicolumn{2}{|c|}{ CG } & \multirow{2}{*}{$\mathbf{p}$} \\
\hline & $\mathbf{n}$ & $\%$ & $\mathbf{n}$ & $\%$ & \\
\hline Follow-up & 19 & $(9.50)$ & 45 & $(22.50)$ & $<0.001$ \\
\hline Burning/stinging & 63 & $(31.50)$ & 66 & $(33.00)$ & 0.748 \\
\hline Pain & 30 & $(15.00)$ & 30 & $(15.00)$ & 1.000 \\
\hline Redness & 41 & (20.50) & 42 & $(21.00)$ & 0.902 \\
\hline Swelling & 11 & $(5.50)$ & 9 & $(4.50)$ & 0.646 \\
\hline Hyperopia & 22 & $(11.00)$ & 74 & $(37.00)$ & $<0.001$ \\
\hline Myopia & 55 & $(27.50)$ & 57 & $(28.50)$ & 0.824 \\
\hline Itching & 21 & $(10.50)$ & 16 & $(8.00)$ & 0.388 \\
\hline Crusting/discharge & 5 & $(2.50)$ & 9 & $(4.50)$ & 0.276 \\
\hline Diplopia & 2 & $(1.00)$ & 1 & $(0.50)$ & 0.562 \\
\hline
\end{tabular}

Chi-square test

Abbreviations: CovG: Group during COVID-19 pandemic, CG: Control group, pre-COVID-19

Table 3. Comparison of groups in terms of the presence of chronic eye disease

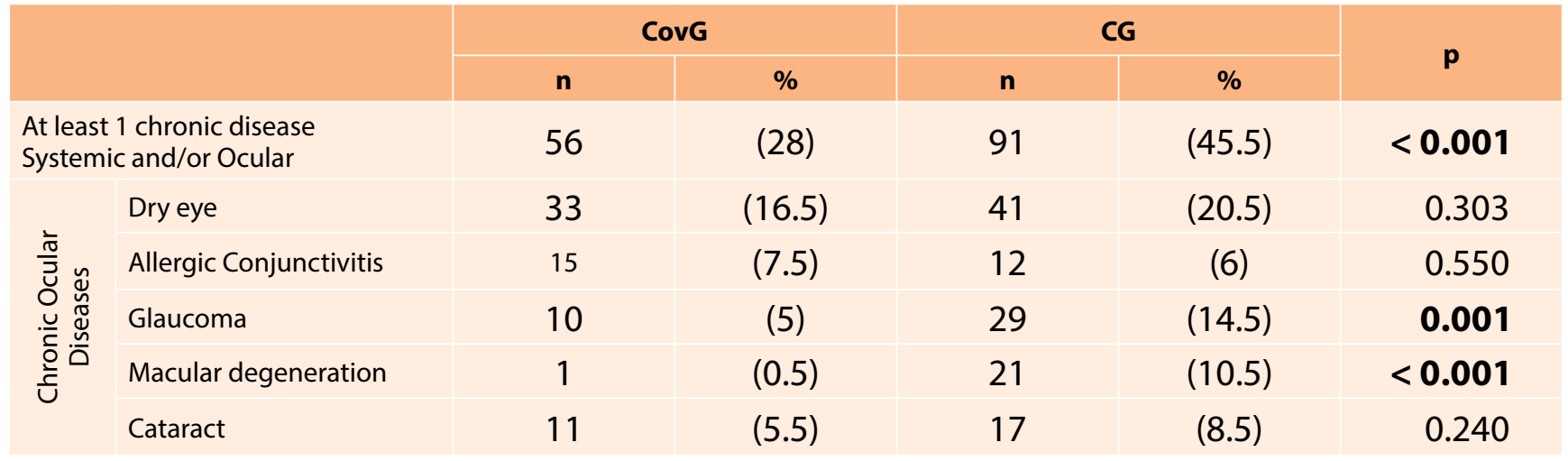

Chi-square test

Abbreviations: CovG: Group during COVID-19 pandemic, CG: Control group, pre-COVID-19 
The groups were also compared in terms of chronic diseases such as hypertension, diabetes mellitus and atherosclerotic heart disease. Table 3. At least 1 systemic and/or ocular chronic disease was present in 56 patients $(28.00 \%)$ in the CovG and in 91 patients $(45.50 \%)$ in the CG ( $p<0.001)$. Comparison of the prevalence of dry eye, allergy, glaucoma, macular degeneration and cataract between the two groups, showed that there were significantly more glaucoma patients in the CG $(n=29$, $14.5 \%)$, compared to the CovG $(n=10,5.0 \%)(p=0.001)$. There was only 1 patient $(0.50 \%)$ with age-related macular degeneration in the CovG, compared to 21 patients $(10.50 \%)$ in the CG $(p<0.001)$.

\section{DISCUSSION}

With the dramatic global impact of the COVID-19 pandemic, there have been important changes in reasons for outpatient presentation, resulting from calls for social isolation, people not leaving their homes except for essential needs and public fear. The significantly lower mean age of individuals presenting to the outpatient clinic during the pandemic compared to the pre-pandemic period, is noteworthy. This difference in mean age may be due to the fact that our study examined the most intense period of the pandemic in our country, during which a stay-at-home order for those over 65 years of age was in force.

While males predominated among outpatient presentations in the pre-COVID-19 period, the equalization of the female to male ratio suggests that there may be a difference between the genders in terms of risk perception.

We believe that this increase in the proportion of female patients during the pandemic could be due to the fact that the active substance hydroxychloroquine is also used in COVID-19 treatment, and patients with dry eye associated with rheumatic diseases in particular, may have been anxious to obtain the drug. Moreover, the significant decrease in the number of university graduates presenting during the pandemic, suggests that education level may be associated with risk perception.

The COVID-19 pandemic caused significant changes in the distribution of the presenting complaints and diagnoses of ophthalmology outpatients (Table 2, Table 3). In our study, we observed no relative increase in any eye disease compared with the pre-pandemic period. Some diseases showed no statistically significant change (dry eye and allergic conjunctivitis) and others significantly decreased in frequency (glaucoma and macular degeneration). Patients diagnosed with dry eye and allergic conjunctivitis presented more often during the pandemic, but the difference was not significantly higher than in the pre-pandemic period ( $p=0.748$ ). In our study, we noted that the proportion of patients with diseases that require periodic follow-up eye examinations, such as glaucoma and age-related macular degeneration, was significantly lower during the pandemic. This may also be due to the stay-at-home order issued for those over 65 years of age.
Significant changes in disease frequency distributions during the pandemic have been reported in branches other than ophthalmology $[12,13]$. In these studies, the researchers formed control groups from patients who presented a few weeks prior to the first detection of COVID-19 in Turkey and thus could not exclude the effect of seasonal presentations. The control group in the present study consisted of outpatient presentations to the ophthalmology department, during the same 30-day period of the previous year. The only significant differences in the distribution of presenting complaints before and during the pandemic, were seen for hyperopia and follow-up for all causes. In an extraordinary period like the COVID-19 pandemic, it is conceivable that the diagnosis distribution may change for reasons such as differences in perceived risk due to factors such as age, comorbidities and occupation, increased social stress as well as changes in personal hygiene habits. In our study, the median age of the patients was 49 before the pandemic and 41 during, which may explain the decrease in presentations due to hyperopia. We believe that the change in median age is attributable to the stay-at-home order for those over age 65.

An interesting finding of this study was that patients with dry eye accounted for the most outpatient appointments in our ophthalmology department at the peak of the pandemic in Turkey. Dry eye disease has been shown to have an adverse impact on quality of life (QoL), in particular in patients with severe dry eye [14]. At the height of the pandemic, the Turkish Ministry of Health extended prescription validity periods in order to enable those with chronic diseases to obtain their drugs from the pharmacy without having to go to the hospital. The fact that these patients could have obtained their drugs without undergoing examination, but still presented to an ophthalmologist, is an indicator of the negative effect of this disease on QoL.

Moreover, there was no decrease in the presentation rate of patients diagnosed with allergic conjunctivitis during the pandemic. Because dry eye and allergic conjunctivitis significantly affect patients' QoL, the patients' need for medical advice may have overtaken their perceived COVID-19 risk.

A significant decrease was observed during the pandemic in the proportion of patients presenting with diseases associated with advanced age, such as glaucoma and macular degeneration. Of course, the prevalence of these diseases in the population did not decrease as a result of the pandemic. More likely explanations for the decline in outpatient admissions among these patients are that COVID-19 is more life-threatening in older patients, that sudden worsening is rare in these age-related ocular diseases, that the patients' perceived risk was similar, that treatment for chronic diseases is planned in the long term and that restrictions were in place for individuals aged 65 years and over.

Limitations of our study include its retrospective nature, the small patient groups and lack of detailed clinical findings, as well as the fact that patients were not assessed for depression, anxiety, QoL, or individual COVID-19 risk 
perception. In addition, not all patients of the pre-pandemic period that constituted the control group were included in the analysis, but an attempt at bias mitigation was attempted through random sampling using a computer program. The strength of this study is that it is the first and only study to analyze the distribution of presenting complaints and diagnoses in an outpatient ophthalmology clinic, during the COVID-19 pandemic.

\section{CONCLUSION}

This study was conducted in order to understand why patients with ophthalmic conditions of low urgency and mortality presented to the hospital during a deadly global pandemic. Patients with dry eye accounted for the highest number of ophthalmology outpatient appointments during the peak of the pandemic in Turkey. In the Covid-19 pandemic period, patients with age-related macular degeneration and glaucoma diagnosed with the potential to cause vision loss will have fewer outpatient applications, so it will be beneficial to check these patients with video consultation / telemedicine.

\section{Acknowledgements}

The authors would like to thank Dr. Nedime Şahinoğlu Keşkek for her valuable contributions which greatly improved this article.

\section{LITERATURA}

1. Guo YR, Cao QD, Hong ZS, et al. The origin, transmission and clinical therapies on coronavirus disease 2019 (COVID-19) outbreak - an update on the status. Mil Med Res. 2020;7:11.

2. Republic of Turkey Ministry of Health, General Directorate of Public Health. COVID-19 (SARS-CoV2 Infection) Guide (Science Board Study): General information, epidemiology and diagnosis. Republic of Turkey Ministry of Health website. June 1,2020. Accessed June 4,2020. https://covid19bilgi.saglik.gov.tr/depo/rehberler/covid-19-rehberi /COVID-19_REHBERI_GENEL_BILGILER_EPIDEMIYOLOJI_VE_TANI.pdf

3. Global surveillance for COVID-19 caused by human infection with COVID-19 virus: interim guidance. World Health Organization; March 20, 2020.

4. https://www.icisleri.gov.tr/65-yas-ve-ustu-ilekronik-rahatsizligi-olanlara-sokaga-cikmayasagi-genelgesi. 21.03.2020.

5. https://www.icisleri.gov.tr/koronavirus-tedbirleri-genelgesi-kapsaminda-149382-is-yerigecici-sureligine-faaliyetlerine-ara-verdi.

6. Important coronavirus updates for ophthalmologists. American Academy of Ophthalmology website. https://www.aao.org/headline/alert-important-coronavirus-context. Updated March 25, 2020. Accessed March 29, 2020.

7. Bozkurt B, Eğrilmez S, Şengör T, Yıldırım Ö, İrkeç M. The COVID-19 Pandemic: Clinical Information for Ophthalmologists. Turk J Ophthalmol. 2020;50:59-63
8. Xia J, Tong J, Liu M, Shen Y, Guo D. Evaluation of coronavirus in tears and conjunctival secretions of patients with SARS-CoV-2 infection. J Med Virol. 2020 Feb 26. doi: 10.1002/jmv.25725.

9. Lu C-w, Liu X-f, Jia Z-f. 2019-nCoV transmission through the ocular surface must not be ignored. Lancet. 2020;395:e39.

10. Jun ISY, Anderson DE, Kang AEZ. Assessing Viral Shedding and Infectivity of Tears in Coronavirus Disease 2019 (COVID-19) Patients. Ophthalmology. 2020;127:977-979.

11. Seah I, Agrawal R. Can the coronavirus disease 2019 (COVID-19) affect the eyes? A review of coronaviruses and ocular implications in humans and animals. Ocul Immunol Inflamm. 2020;28:391-395.

12. Turan Ç, Metin N, Utlu Z, Öner Ü, Kotan ÖS. Change of the diagnostic distribution in applicants to dermatology after COVID-19 pandemic: What it whispers to us? Dermatol Ther. 2020 Jun 12:e13804. doi: $10.1111 /$ dth.13804.

13. Cengiz AB, Tansuker HD, Oktay MF. The Features of the Patients Who Attend to Otorhinolaryngology Outpatient Clinics in the First Days of the COVID-19 Outbreak in Turkey? KBB ve BBC Dergisi. 2020 May 12. doi: 10.24179/kbbbbc.2020-76082. Turkish.

14. Wu M, Liu X, Han J, Shao T, Wang Y. Association Between Sleep Quality, Mood Status, and Ocular Surface Characteristics in Patients With Dry Eye Disease. Cornea. 2019 Mar;38:311-317. doi: 10.1097/ ICO.0000000000001854. 